Anna Echterhölter/ Jens Schröter/ Andreas Sudmann

\title{
How is Artificial Intelligence Changing Science? Research in the Era of Learning Algo- rithms
}

\section{Introduction}

Since its inception, artificial intelligence (AI) has been discussed in terms of its radical transformative potential, how it may or will, at some point in the future, fundamentally change art, technology, or the whole society. Even today, as ongoing discussions around the event of a technical singularity illustrate, the question of a caesura caused by AI continues to be a utopian or dystopian imagination. And many experts believe that we are already in the middle of such a revolution that will be bigger and more significant than anything we have seen before. Such inflationary rhetoric of superlatives, which not only characterizes the PR talk of Silicon Valley's leading tech companies, but also the beliefs of many computer scientists, almost inevitably prompts criticism. ${ }^{1}$ Indeed, when the discourse of AI as disruptive technology has become so ubiquitous, it is very tempting to question this assumption. In the humanities and cultural studies distrust in technological futurism is deeply entrenched, mostly for good reasons. At the same time habitual reflexes against technological revolutions run the risk to exhaust themselves in an "hermeneutics of suspicion". ${ }^{2}$ Beyond this global criticism it seems advisable to critically investigate technological innovation right around the corner, for instance European universities, to find an angle for the necessary juridical regulatory framework every new technology triggered.

However, at least this much can be stated with certainty: the current upswing in AI can essentially be attributed to one approach, i.e. the machine learning methods of artificial neural networks (ANN). Whether in terms of self-driving cars, stock market predictions, or facial recognition software, it can be assumed that this specific form of connectionist AI is decisively involved in almost every "smart" application. Remarkably enough, approaches of machine learning in general and ANN in particular are anything but new, since their essential foundations were already developed in the 1940s and 1950s, by scientists such as Warren McCulloch, Walter Pitts or Frank Rosenblatt. Nevertheless, the applicability of machine learning methods has

\footnotetext{
${ }^{1}$ Lynch, Shana. 'Andrew Ng: Why AI Is the New Electricity'. Stanford Graduate School of Business, 3 November 2017. https://www.gsb.stanford.edu/insights/andrew-ng-why-ai-new-electricity.

${ }^{2}$ We borrow the term here from Paul Ricoeur in a very loose way, since his concept can easily be used to disavow any form of criticism.
} 
been limited to comparatively simple tasks in the past. ANN were even considered a dead end in AI research. The latter view in particular has now turned out to be a misjudgment. ${ }^{3}$

As it turns out, this specific form of $\mathrm{AI}$ is interfering with all areas of culture and society, including the practices and methods of research in the humanities and sciences. In biology, ANN are already used for making genomic connections. In art history, deep learning algorithms help to study damage in art works and replicate them precisely. In criminology, machine learning based AI systems are used for the purpose of predictive policing, i.e. to learn more about when and where a crime is likely to take place. ${ }^{4}$

Indeed, the current boom in AI has also raised anew the question of its specific role in science, leading to the revisiting of old epistemological perspectives that have accompanied AI research for decades. Can we and how can we (eventually) delegate research in all its possible dimensions to AI? How can AI contribute to the automation of scientific thinking and working processes? And should this be the case, would it be reasonable and desirable?

We are convinced that these questions have gained a new relevance at this very moment of history, but that they require a specific and critical socio-epistemological perspective across all disciplines. It is necessary to investigate how AI procedures are already changing or amplifying the methodical practices of science, how research is done with AI rather than on AI. Our focus is less on the future consequences of $\mathrm{AI}$, but to critical evaluate the current conditions of using AI as a ubiquitous tool, which amplifies and enhances preexisting methodological elements across the sciences and the humanities. Such a project requires not only a solid foundation in the current applications of AI, which we observe with ethnographic methods, but also a profound historical and theoretical analysis, partly because AI research itself, since its beginnings, has always been an inter- or transdisciplinary enterprise posing fundamental methodological questions beyond singular perspectives. It is therefore all the more important to take a closer look at how AI concretely intervenes in the work of researchers, in their academic practices and methods, how it is applied in detail, and how it is reflected upon by the actors, not only in the natural sciences, but also in the humanities and social sciences.

In what follows, we will discuss some of the urging epistemological and methodological challenges and potential framings of these questions. We will also turn to the role of machine learning in particle physics, since it is the pioneering field in the use of machine learning, as a

\footnotetext{
${ }^{3}$ For early reflections on this technology's impact see Vinge, Vernor. 'The Coming Technological Singularity: How to Survive in the PostHuman Era'. VISION-21 Symposium, 1993, 11-22. https://ntrs.nasa.gov/archive/nasa/casi.ntrs.nasa.gov/19940022855.pdf.; For more detail and literature on the history of machine learning and ANN, see Sudmann, Andreas. 'Einleitung'. In Machine Learning. Medien, Infrastrukturen und Technologien der Künstlichen Intelligenz, by Christoph Engemann and Andreas Sudmann, XX. Bielefeld: Transcript, 2018.

${ }^{4}$ Webb, Sarah. 'Deep Learning for Biology'. Nature 554 (2018): 555-57.; Adam, David. 'From Brueghel to Warhol: AI Enters the Attribution Fray'. Nature 570 (2019): 161-62. ; McDaniel, John, and Ken Pease, eds. Predictive Policing and Artificial Intelligence. Abingdon, New York: Taylor \& Francis, 2021.
} 
historical case study to properly contextualize the current challenges in different areas of academia.

\section{AI in academia}

At present, it is fair to claim that the AI boom has already affected the vast majority of academic disciplines in various ways. For example, only within the framework of our research group, we were able to identify over 200 projects in Europe that are currently using AI as a method in some form, just with regard to the selected six disciplines of our research scope. ${ }^{5}$ Some disciplines, especially from the field of the humanities, have more or less just started to explore how they might methodically use AI in their work, while other disciplines such as physics or geosciences have been using machine learning and ANN for decades. For example, as Jesper Sören Dramsch has recently pointed out, machine learning approaches have been used in the geosciences as early as the $1960 .{ }^{6}$ Nevertheless, the recent technical advances of ANN in the fields of speech recognition (since about 2009) and image recognition (since 2012) have provided a boost also in those areas of academic research which already have a long tradition of expertise in $\mathrm{AI}$ and machine learning.

Indeed, AI has been associated with a new empiricism, since machine learning methods have long been involved in all kinds of data analyses: from the exploration and collection of information to its analysis and evaluation. However, the exact epistemic-technical status of AI procedures is quite different in all of its applications. An important and general function of machine learning across disciplines is obviously to optimize existing and established processes of scholarly work and the automation of practices previously done (only) by humans. ${ }^{7}$ Furthermore, AI in general and machine learning in particular are meant to fulfill tasks that were not previously possible at all. But can machine learning approaches also formulate interesting, surprising hypotheses and literally enable new scientific discoveries or perform them independently? Many experts believe that we have already entered this stage of development. DeepMind recently published a study that, according to its self-description, is supposed to demonstrate "how artificial intelligence research can drive and accelerate new scientific discoveries", introducing

\footnotetext{
${ }^{5}$ How is Artificial Intelligence Changing Science? 'AI Projects in Europe', 2021. https://howisaichangingscience.eu/ai-projects-in-europe/.

${ }^{6}$ Ramsch, Jesper Sören. '70 Years of Machine Learning in Geosciencein Review'. Advances in Geophysics 61 (2020): 1-55. https://doi.org/https://doi.org/10.1016/bs.agph.2020.08.002.

${ }^{7}$ This does not mean that these practices are automated $1: 1$, but that significant epistemic-technical shifts also occur, that is, that work is substantially reconfigured as an effect.
} 
a system called AlphaFold that is able to predict the 3D structure of proteins based solely on their genetic sequencing. ${ }^{8}$

However, the possibilities of AI to discover something new are viewed critically by some scholars. For example, according to media philosopher and critical AI researcher Matteo Pasquinelli ANN are operating purely inductively. Due to the fact that the corresponding models are always trained with known, existing data, they are therefore unable, as Pasquinelli, argues, to perform what is called abduction in the sense of Peirce, in other words, they are ultimately incapable of generating something emphatically new. ${ }^{9}$

This is one position. At the same time, many computer scientists are motivated by the goal and do believe in the possibility of developing an artificial general intelligence, which would then also include the ability of abduction. Of course, a potential artificial general intelligence does not have to be human-like. Nevertheless, the question arises as to what it means when machines challenge and produce scientific knowledge without human passion, self-doubt and the will to know?

In fact, for decades there have been attempts to breathe into machines those very anthropological characteristics that constitute the process of science as a profoundly human practice. For example, someone who has been working towards this ambitious goal for many years is the well-known AI researcher Jürgen Schmidhuber. In talks and interviews, he regularly mentions his childhood dream of developing an AI that would be better than himself, and he is one of the now famous utopists in the AI community who is deeply convinced that a machine capable of surpassing humans in all conceivable areas could become a reality in the not too distant future. Indeed, already in his final thesis of 1987, Schmidhuber was researching meta-algorithms capable of self-optimization. A few years later, he set up a general formal theory of fun, intrinsic motivation and creativity, which is based on the concept of maximizing intrinsic rewards for the creation and discovery of something new. ${ }^{10}$ And yet, it is not his work in the field of selfoptimizing algorithms Schmidhuber's name is typically associated with. Rather, his central merit is to have co-developed (together with Sepp Hochreiter) the so-called LSTM technology, a specific form of a recurrent neural network. After all, computers need some kind of recurrent architecture or system in order to understand the world around them, including human language and meaning. And such a common sense understanding of the world seems in turn to be a

\footnotetext{
${ }^{8}$ Senior, Andrew et al.. 'AlphaFold: Using AI for Scientific Discovery'. Deep Mind, 15 January 2020. https://deepmind.com/blog/article/AlphaFold-Using-AI-for-scientific-discovery.

${ }_{9}^{9}$ Pasquinelli, Matteo. 'Machines That Morph Logic: Neural Networks and the Distorted Automation of Intelligence as Statistical Inference'. Logic Gate: The Politics of the Artifactual Mind, 2017. https:/www.glass-bead.org/article/machines-that-morph-logic/?lang=enview.

10 Jürgen Schmidhuber in Metzler, Marco. 'Jürgen Schmidhuber: «Die Geschichte Wird Nicht Mehr von Menschen Dominiert»'. NZZ am Sonntag, $212017 . \quad$ https://nzzas.nzz.ch/gesellschaft/juergen-schmidhuber-geschichte-wird-nicht-mehr-von-menschen-dominiertld.1322558?reduced=true\#back-register.
} 
central prerequisite for smart machines in order to creatively deal with their environment or to discover something profoundly new. In this area, too, scientists working with ANN have been able to achieve considerable progress in recent years. The same applies to the simulation of creative processes, due to specific technologies of ANN like generative adversarial networks or creative adversarial networks.

\section{How to make sense of AI's transformative potential. Three analytic perspectives}

Regardless, the critique of AI and the evaluation of its critical potential should not focus solely on future scenarios of its potential applicability. Meanwhile, there are already some important theses that try to grasp the fundamental techno-epistemic shift connected to current AI technology beyond the concept of a technical singularity.

1) One of these concepts is the end of theory, as suggested by Chris Anderson in 2008, however, not in relation to $\mathrm{AI}$ in the narrower sense, but more generally with regard to the epistemic role of big data. In fact, the article does not even explicitly mention AI or machine learning, but speaks rather vaguely of "statistical tools". Anderson: "The new availability of huge amounts of data, along with the statistical tools to crunch these numbers, offers a whole new way of understanding the world. Correlation supersedes causation, and science can advance even without coherent models, unified theories, or really any mechanistic explanation at all."11

2) Nevertheless, the thesis of the end of theory is only now gaining relevance in the age of learning algorithms. Especially in view of a second thesis that claims to describe another ending, i.e. the end of code. Indeed, approaches of machine learning like ANN can master problems and solve tasks without being explicitly programmed to do so. Hence, scientists and engineers no longer program machines, but train them: "First we write the code, then the machine expresses it. This worldview implied plasticity, but it also suggested a kind of rules-based determinism, a sense that things are the product of their underlying instructions. Machine learning suggests the opposite, an outside-in view in which code doesn't just determine behavior, behavior also determines code. Machines are products of the world." 12

3) And finally, there is a third thesis that focuses on the transformative potential of current AI technologies. According to this thesis, ANN as a quasi-analog information technology represent a significant break with the functional logic of digital computers according to the Von Neumann

\footnotetext{
11 Anderson, Chris. 'The End of Theory: The Data Deluge Makes the Scientific Method Obsolete'. WIRED, 23 June 2008. https://www.wired.com/2008/06/pb-theory/.

12 Tanz, Jason. 'Soon We Won't Program Computers. We'll Train Them Like Dogs'. WIRED, 17 May 2017. https://www.wired.com/2016/05/the-end-of-code/?code=cf516G16Cxh0Jr_HDAVrbKvz21OtYXb0EhA9j7Rkw_D\&state=\%7B\%22redirectURL $\% 22 \% 3 \mathrm{~A} \% 22 \mathrm{https} \% 3 \mathrm{~A} \% 2 \mathrm{~F} \% 2 \mathrm{Fwww}$.wired.com $\% 2 \mathrm{~F} 2016 \% 2 \mathrm{~F} 05 \% 2 \mathrm{Fthe}$-end-of-

code $\% 2$ F\%3Futm_source $\% 3$ DWIR_REG_GATE\%22\%7D\&utm_source=WIR_REG_GATE.
} 
architecture, which is still dominant today. Although ANN run on digital computers, they are an equivalent model of a Turing machine in terms of computability, what distinguishes them as machines is the massive parallelism of information processing. This is the core property of ANN or deep learning and essential for the specific performance in dealing with big data. ${ }^{13}$

Our preliminary thesis is that all three theoretical perspectives are central not only to adequately assessing the transformations in science brought about by AI, but equally to fathoming its political and social dimensions of change, which we will address at the end of this essay. But before doing so, we want to take a closer look at the field of particle physics and in particular at the discovery of the Higgs-boson in 2012, because it is a revealing case study to discuss how approaches of machine learning reconfigure the epistemic status of theory in relation to empirical methods.

\section{A case study: machine learning in particle physics}

So what happened in 2012 in connection with the discovery of the Higgs boson, which is so important to our research interests? To answer this question, we must first delve further into the history of particle physics, more specifically to a spectacular event in 1964 - the discovery of the so-called ' $\Omega$ '.

\footnotetext{
${ }^{13}$ Sudmann, Andreas. 'Szenarien des Postdigitalen. Deep Learning als MedienRevolution'. In Machine Learning. Medien, Infrastrukturen und Technologien der Künstlichen Intelligenz, by Christoph Engemann and Andreas Sudmann, 56-73. Bielefeld: Transcript, 2018.
} 

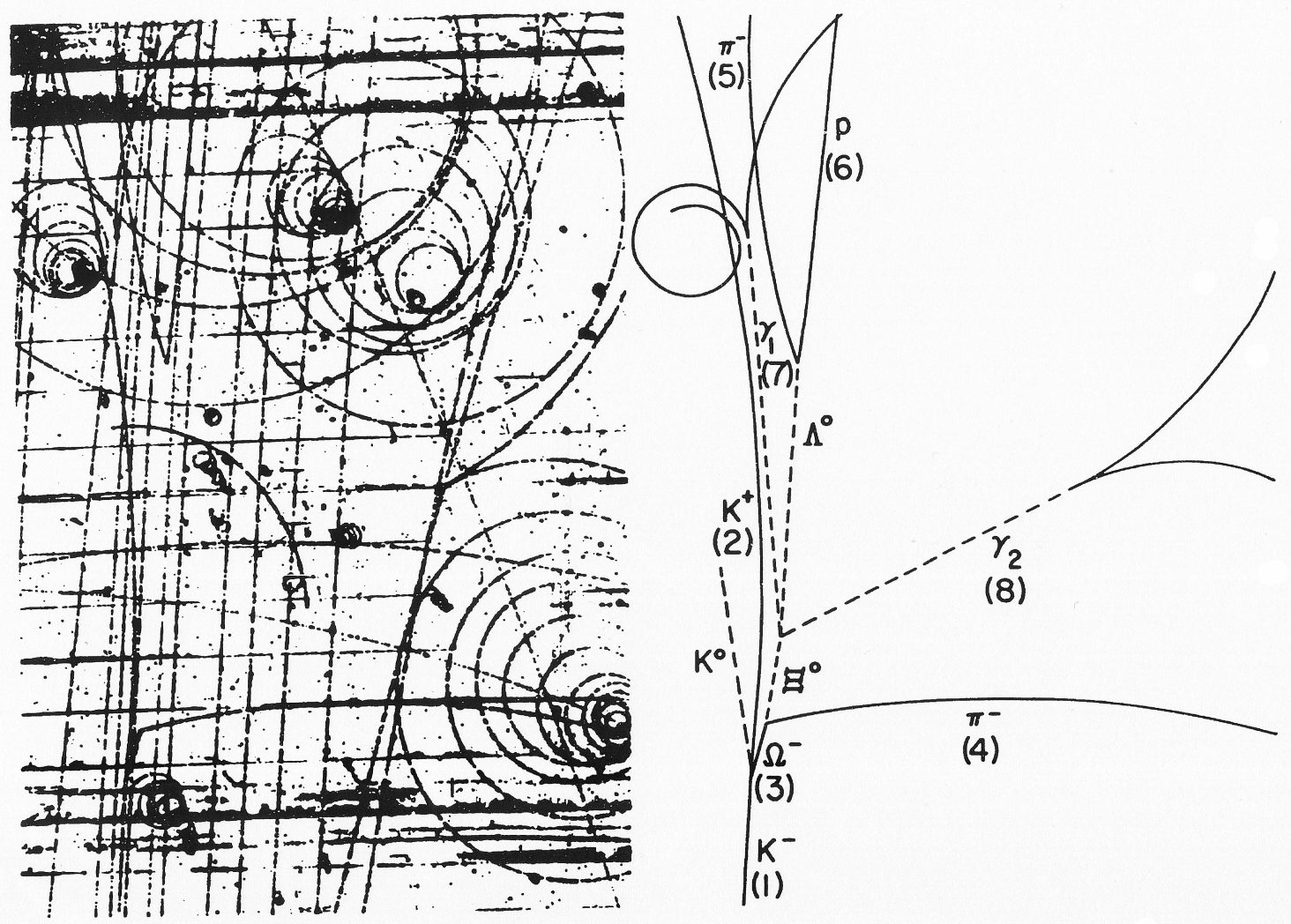

Fig. 1

Photography of Omega Minus-Event with explaining 'line diagram', from: V. E. Barnes et al., 'Observation of a Hyperon with Strangeness Minus Three', in: Physical Review Letters, Vol. 12, No. 8 (24.2.1964), pp. 204-206 (205, processed).

This image shows one of the most important photos from the history of particle physics, a golden event, as Peter Galison has called it. ${ }^{14}$ If one looks at the photo without context information, you basically can't see anything on it. One cannot say what is depicted - because reference depends on knowledge. ${ }^{15}$ Together with the commenting line diagram, such as it is printed in the nowadays legendary publication of $1964^{16}$, the image becomes meaningful, the pattern can be recognized. The line diagram shows which traces are important. Symbols are added to the lines, which make - at least for experts - clear which traces of what particles are

\footnotetext{
${ }^{14}$ See Galison, Peter. Image and Logic. A Material Culture of Microphysics. Chicago: University of Chicago Press, 1997.

${ }^{15}$ See Elgin, Catherine. With Reference to Reference. Indianapolis: Hackett, 1983.

${ }^{16}$ See Barnes, V. E. et al. 'Observation of a Hyperon with Strangeness Minus Three'. Physical Review Letters 12, no. 8 (24 February 1964): 204-6.
} 
represented. The numbers in parentheses point to additional information in the text. More detailed arguments for the interpretation of the traces are given there.

This specific photograph is marked with the number 97,025 of a series of experiments conducted at the Brookhaven Laboratory, New York. ${ }^{17}$ In this laboratory for particle physics, researchers had set up a bubble chamber filled with approximately 1,000 litres of hydrogen. A beam of negatively charged kaons, a special kind of particle produced at the lab, was shot into the laboratory's 80-inch tall bubble chamber. During the collisions of the beam with the atoms, numerous new particles arose which, dependent on their charge and their mass, left behind traces resembling tiny condensation trails. But only one particle interested the researchers namely the particle with the name ' $\Omega$ ', . Murray Gell-Mann was the first person to assert the existence of this particle as early as 1962 to his colleagues at an international conference. GellMann could predict the particle and its precise characteristics, since he had discovered a new regularity in the previously rather confusing particle zoo, namely the so-called ' $S U(3)$ symmetry'. ${ }^{18}$ This theory was confirmed by the 'evidence' of the traces on photo number 97,205 from 1964. The simple fact that it was the 97,205th image on which the sought-after traces occurred demonstrates how much work with media had been put into the particle chase. A film was passed at high speed over the bubble chamber in order to capture the countless and disorganized collision events. After the bombardment had ended, the film had to be evaluated one image at a time. For this purpose, there were entire teams of specialists (called 'scanners') who looked out for suspicious traces. If these were found, they then had to be interpreted. The length of the traces was measured and they were inserted into complicated models that were running on digital computers. This was a highly complex process, which was (in a general form) described in detail in a 1967 paper with the title "Man-Machine Cooperation in Digital Pattern Recognition of Bubble Chamber Tracks". ${ }^{19}$ The interesting point here is that the notion of "pattern recognition" was already used back then to describe the discovery of predicted structures in the bulk of photographic data. ${ }^{20}$ But this pattern recognition had to be stabilized over time: At the time of its production in 1964, the mentioned image was not yet recognized as the

\footnotetext{
${ }^{17}$ See Samios, Nicholas. 'Early Baryon and Meson Spectroscopy Culminating in the Discovery of the Omega Minus SU(3) and Quarks'. Stanford: Brookhaven National Lab., 1993. See also Samios, Nicholas. 'Early Baryon and Meson Spectroscopy Culminating in the Discovery of the Omega-Minus and Charmed Baryons'. In The Rise of the Standard Model. Particle Physics in the 1960s and 1970s, edited by Lillian Hoddeson et al., 525-41. New York: Cambridge University Press, 1997.

${ }^{18}$ On the history of quark physics see Pickering, Andrew. Constructing Quarks. A Sociological History of Particle Physics. Chicago: University of Chicago Press, 1984. See also Brown, Laurie M. 'The Rise of the Standard Model: 1964-1979'. In The Rise of the Standard Model. Particle Physics in the 1960s and 1970s, edited by Lillian Hoddeson et al., 3-35. New York: Cambridge University Press, 1997.

See also Wolfgang Hagen, Wolfgang. 'Das Atlantische Standard Modell - Anmerkungen Zu Einer Genealogie Der Elektrizität Und Ihrer Medien', 2014. http://www.whagen.de/PDFS/07953_HagenDasatlantischeStanda_2014.pdf.

${ }^{19}$ See Strand, R.C. 'Man-Machine Cooperation in Digital Pattern Recognition of Bubble Chamber Tracks'. Annals of the New York Academy of Sciences 157, no. 1 (1967): 65-82.

${ }^{20}$ See on the notion of "photographic data" Blaschke, Estelle. 'From Microform to the Drawing Bot: The Photographic Image as Data'. Grey Room 75 (2019): 60-83.
} 
evidence we see it as today. Only as further indications began to accumulate ${ }^{21}$, the image was recognized as the first photo of an event during which an omega minus boson has been produced and disintegrated. The photograph convinced most physicists that Murray Gell-Mann's theory was correct (he received the Nobel Prize in 1969) - today, it has become one of the supporting pillars in the so-called 'standard model of particle physics' under the heading 'quark model'. Already in the 1960s in the then emerging standard model, the Higgs mechanism and its associated boson played a crucial role. ${ }^{22}$ They were postulated in a short paper, also published by coincidence in 1964. For a long time, the boson existed only hypothetically and was demanded to explain the process of electroweak symmetry breaking. The detection of this particle - or at least of a very similar boson - was finally announced at CERN in 2012. Basically, the process was similar to the Omega Minus: There was a theoretical model that predicted a particular particle. And now the task was to test whether or not this model correctly described nature. Could this particle be found?

The search for the Higgs boson is the main example in a paper from Nature on the role of machine learning in particle physics. Interestingly, the text begins with a review of the bubble chambers and visual pattern recognition methods that we just discussed in relation to the ' $\Omega$ '.' We quote in length from the paper in Nature:

"Many known particles were discovered using detectors that made subatomic particles visible to the human eye. For example, bubble chambers filled with superheated liquids that boil when charged particles pass through them transform the paths of the particles into visible tracks of bubbles, which can then be photographed and analysed. The detectors at the Large Hadron Collider (LHC) are much more complex and record data at far greater rates than is possible using bubble chambers. For example, the LHCb experiment analyses as many events every six seconds as the Big European Bubble Chamber recorded in its entire 11 years of operation (1973-1983), and the datasets collected by the ATLAS and CMS experiments at the LHC are comparable to the largest industrial data samples. It is impossible for humans to visually inspect such large amounts of data; algorithms running on large computing farms took over this task long ago." 23

Obviously, the information processing capacities of humans are not sufficient to cope with the gigantic amounts of data. This becomes even clearer in the following quote.

"The sensor arrays of the LHC experiments produce data at a rate of about one petabyte per second. Even after drastic data reduction by the custom-built electronics used to readout the

\footnotetext{
${ }^{21}$ It was for example important that experiments in "deep inelastic scattering”, beginning around 1967, had shown protons as having a deeper structure which gave credibility to the idea of quarks being real physical entities and not only helpful mathematical constructions, see Friedman, Jerome. 'Deep-Inelastic Scattering and the Discovery of Quark'. In The Rise of the Standard Model. Particle Physics in the 1960s and 1970s, edited by Lillian Hoddeson et al., 566-88. New York: Cambridge University Press, 1997.

${ }^{22}$ See Brown, Laurie M. 'The Rise of the Standard Model: 1964-1979'. In The Rise of the Standard Model. Particle Physics in the 1960s and 1970s, edited by Lillian Hoddeson et al, 12-16. New York: Cambridge University Press, 1997.

${ }^{23}$ Radovic et al. (2018). Machine learning at the energy and intensity frontiers of particle physics. Nature, 560, 41-48.
} 
sensor arrays, which involves zero suppression of the sparse data streams and the use of various custom compression algorithms, the data rates are still too large to store the data indefinitelyas much as 50 terabytes per second, resulting in as much data every hour as Facebook collects globally in a year." 24

But why do these systems have to produce so much data?

"Einstein famously related mass $\mathrm{m}$ to energy $\mathrm{E}$ via $\mathrm{E}=\mathrm{mc}^{2}$, where $\mathrm{c}$ is the speed of light in a vacuum. A powerful particle accelerator such as the LHC, which is $27 \mathrm{~km}$ in circumference, is therefore required to create particles orders of magnitude more massive than the proton, such as the Higgs boson. A Higgs boson is produced only once every few billion proton-proton collisions at the LHC. Many other interesting reactions occur orders of magnitude less often. To enable such data samples to be recorded in a reasonable time frame, the LHC collides nearly one billion protons per second." 25

It is necessary to create so many data on so many events because the processes you are looking for are so extremely rare - as the theory predicts.

"As stated above, a Higgs boson is produced only once every few billion proton-proton collisions at the LHC; however, the Higgs boson usually decays in ways that mimic much more copiously produced processes. The cleanest experimental signature of the Higgs boson involves its decay into two muon-antimuon pairs, which occurs roughly once every 10 trillion protonproton collisions. ${ }^{2} 26$

Above all, that means the machine learning methods have the purpose to filter out the events which correspond to the predictions of the theory from the immense noise. But how do the machine learning systems know this?

"The need to understand what signals will look like in the detectors and what other processes can mimic the signals has led to the development of high-quality simulation tools. Furthermore, the standard model provides accurate predictions of the rates and kinematic distributions of many of the processes that can mimic interesting signatures (referred to as backgrounds) and that contribute to particle-physics data samples, providing important benchmarks for validating the simulation tools and understanding their uncertainties. Therefore, simulated data samples are often used to train the machine-learning algorithms because in such samples all information is known by construction." 27

Even if this is simplified and would have to be investigated in much more detail, e.g. by our project, it becomes clear: The analysis of the large amounts of data by the ML systems succeeds by training them with simulations according to the theory of the standard model. In a way, the

\footnotetext{
${ }^{24}$ Radovic et al. (2018). Machine learning at the energy and intensity frontiers of particle physics. Nature, 560, 41.

${ }^{25}$ Ibid.

${ }^{26} \mathrm{Ibid}$.

${ }^{27}$ Ibid., 45.
} 
AI systems, 'know' what to look for. This shows that without the performative models of simulation, as Licklider had already called them in $1967^{28}$, data analysis would not work. Simulation stands between the theoretical model, let's say the theory of the Higgs-mechanism, and the raw data. Simulations perform the theory so that template-patterns can be generated that can be used to train the machine learning systems.

The application of AI in research essentially means pattern recognition, especially with regard to artificial neural networks and other forms of machine learning that deal with huge amounts of data. There is continuity to past scientific practices that were also already pattern recognition in (photographic) data but with the difference that today we have a lot more data - the systems find patterns that humans can no longer recognize. The ML systems are in turn trained with data, but data that - at least in the example here - is itself generated by simulations, simulations that are in turn based on theoretical models. The latter should be emphasized if we once again take into account Chris Anderson's thesis that big data and correlations substitute theory and (causal) explanations. Again a longer quote:

“"All models are wrong, but some are useful.' So proclaimed statistician George Box 30 years ago, and he was right. But what choice did we have? Only models, from cosmological equations to theories of human behavior, seemed to be able to consistently, if imperfectly, explain the world around us. Until now. Today companies like Google, which have grown up in an era of massively abundant data, don't have to settle for wrong models. Indeed, they don't have to settle for models at all. [...] The big target here isn't advertising, though. It's science. The scientific method is built around testable hypotheses. These models, for the most part, are systems visualized in the minds of scientists. The models are then tested, and experiments confirm or falsify theoretical models of how the world works. This is the way science has worked for hundreds of years. Scientists are trained to recognize that correlation is not causation, that no conclusions should be drawn simply on the basis of correlation between $\mathrm{X}$ and $\mathrm{Y}$ (it could just be a coincidence). Instead, you must understand the underlying mechanisms that connect the two. Once you have a model, you can connect the data sets with confidence. Data without a model is just noise. But faced with massive data, this approach to science - hypothesize, model, test - is becoming obsolete. [...]." 29

However, at least with regard to the case study discussed here, we must disagree with Anderson's thesis. As one can see exactly at the LHC, data analysis needs models: 'Data without a model is just noise'. The main task of machine learning methods there was to find the tracks predicted by the theory in the noise of the collision events - if they are found, people might win a Nobel prize (as Higgs and Englert did in 2013). If not or if completely different events are found, at least historians of science might take a look at the failed models. 'Hypothesize, model,

\footnotetext{
${ }^{28}$ Cf. J. C. R. Licklider, “Interactive Dynamic Modeling," in Prospects for Simulation and Simulators of Dynamic Systems, ed. George Shapiro et al. (New York: MacMillan 1967), 281-289.

29 Anderson, Chris. 'The End of Theory: The Data Deluge Makes the Scientific Method Obsolete'. WIRED, 23 June 2008. https://www.wired.com/2008/06/pb-theory/.
} 
test' still applies. ${ }^{30}$ Of course, the case study analyzed here cannot be applied unconditionally to other disciplines and academic fields. Especially in the humanities, for example, one often does not operate with hypotheses that are tested experimentally or empirically. At the same time, of course, it might be possible that machine learning techniques in other fields of the natural sciences have relegated the importance of theoretical explanations and approaches. Therefore, it is all the more important to investigate the relationship between theory and empiricism in the age of learning algorithms, and this is exactly what we intend to find out in our research project.

\section{Data driven science}

In addition, the supposed end of theory has a flipside: Voices from the data science community have claimed that data driven science will replace theoretical methods as a fourth scientific paradigm around 2009. In an acclaimed article Rob Kitchin fathomed the potential of this fourth paradigm for a wider set of disciplines in the sciences and humanities in 2014. As a human geographer who advocates critical GIS and radical statistics, Kitchin identifies a wave of empiricism and the onset of an era of data-driven science. The latter was introduced with epistemological aplomb as the "fourth paradigm" of data use, and builds on earlier periods of data use throughout the history of science. ${ }^{31}$ According to the fourth paradigm it is no longer the search for knowledge, which drives the development of the sciences, but sheer availability of data. The solar storm of information unleashed by big data and new analytical "tools", especially machine learning, is changing sciences as well as the humanities. The paradigm was formulated by some of Silicon Valley's most acclaimed data architects, among them Tim Hey and the late James Nicholas Gray. They spoke from the heart of the world's largest data nodes, from the centers of Microsoft Research's eScience community, and they figured as diplomats of the brave new world of data in Washington D.C.

Grey embedds the first three paradigms of data use in a historical medley of experimentalism and empiricism. The epochs of empirical, theoretical and computational science differ in that the procedures performed after the data collection become increasingly complex. Not everything in the four stages is concordant with the history of sciences findings about a (pre) history of big data, but the eminent impact of data availability, which is not self-explanatory for

\footnotetext{
${ }^{30}$ How the research at CERN relates to the discussion on the 'end of code' and on 'postdigitality' mentioned above, cannot be answered here - questions like these will be part of the work in our project.

${ }^{31}$ Hey, Tony, Stewart Tansley, and Kristin Tolle, eds. The Fourth Paradigm: Data-Intensive Scientific Discovery. Microsoft Research, 2009.; Hey, Tony, and Anne Trefethen. 'The Fourth Paradigm 10 Years On'. Informatik Spektrum 42 (2020): 441-447. "eScience” was coined by Director General for Research, Microsoft Research, UK, John Taylor.
} 
research in the Early Modern period and way into the $19^{\text {th }}$ century, for research methods is definitely a shared belief of the eScience community and the history of science. ${ }^{32}$

The first paradigm in which data began to give rise to scientific method according to Gray is data collection and more precisely experimental science, where facts about nature are captured and simply represent or "describe" the world. ${ }^{33}$ Since the early modern period scientists learnt how to use these data for hypothesizing and modelling, a mathematical procedure culminating in the work of Kepler, Newton and Maxwell. Gray does not point to Bacon or the colonial origin of most of the empirical facts, channeled back to Europe by reporting routines of the navy, the chartered companies and various trading networks. ${ }^{34}$ But when Simon Schaffer retraced the origin of the data points given about global tides in Newton's Principia mathematica, he was able to show the affinity of colonialism and empirical data collection, even for a theory of celestial mechanics. ${ }^{35}$

The second paradigm takes data processing one step further. It is a little awkwardly called "theoretical science", and describes scientific modeling and generalizations performed from the Renaissance to the computer age.

The third paradigm hinges on the availability of computational power, which sets on around 1950 and facilitates more than modelling. It leads to simulations, which build complex systems and are researched "as nature". In this perspective, simulations also signify an end of analytical capacity.

In the fourth paradigm, eventually, eScience takes over. Scientists 'look' directly into data bases, all work becomes informatic with necessity, data are frequently published in and by themselves, and software costs dominate experimental research budgets. Detection and collection, as well as analysis and ordering, are automated and performed before scientists even try to begin to make sense of the data. Science then becomes tantamount with data management and 'statistics'.

Compared to approaches of new empiricism, which Rob Kitchin discussed in comparison, ${ }^{36}$ he credits the fourth paradigm of science to be more in tune with postpositivist and situated

\footnotetext{
${ }^{32}$ Aranova, Elena, Christine von Oertzen, and David Sepkoski. 'Introduction: Historicizing Big Data'. Osiris 32, no. 1 (2017): 1-17.

${ }^{33}$ Hey, Tony, Stewart Tansley, and Kristin Tolle, eds. 'Jim Gray on EScience: A Transformed Scientific Method'. In The Fourth Paradigm: Data-Intensive Scientific Discovery, xvii-xxxi, xviii. Microsoft Research, 2009.

${ }^{34}$ Siegert, Bernhard. 'Inquisition Und Feldforschung: Zur These Michel Foucaults Über Die Genese Der Empirischen Wissenschaften Im 16. Jahrhundert'. Modern Language Notes, German Issue 118, no. 3 (2003): 538-56.

${ }^{35}$ Schaffer, Simon. 'Newton on the Beach: The Information Order of Principia Mathematica'. History of Science 47, no. 3 (2009): $243-76$. https://doi.org/10.1177/007327530904700301.

${ }^{36}$ The new empiricism in Kitchin's article refers to a renaissance of quantitative research, not to the Deleuzian reconceptualizations of empiricism. For the latter see Clough, Patricia Ticiento. 'The New Empiricism: Affect and Sociological Method'. European Journal of Social Theory 12, no. 1 (2009): 43-61. https://doi.org/10.1177/1368431008099643.; Adams St. Pierre, Elizabeth. 'The Empirical and the New Empiricisms'. Cultural Studies, Critical Methodologies 16, no. 2 (2016): 111-124. https://doi.org/10.1177/1532708616636147.
} 
approaches to data. A relapse into overcome and simplified notions of data neutrality, objectivity and stable reference to nature was less likely, or so he contends. As long as the fourth paradigm builds on previous stages of data use, it relies on the history of statistics and the empirical sciences, which Kitchin does not change. Albeit, with a more finely grained historical view, the four paradigms of data use might be forced to shift somewhat. For example, the important turn towards data in Early Modern empiricism is omitted, or the same is true for the $19^{\text {th }}$ century probabilistic revolution in statistics, which opens up the future for calculation, but deemphasizes the singular data point in its indexicality. ${ }^{37}$ Kitchen emphasizes the fact that new types of measurement have had the potential to change epistemologies and a profound impact on styles of thinking. But the latter words become problematic, since he predicts that data driven science can be seen as a mode of fully capable automated thinking: it "radically modifies the existing scientific method by blending aspects of abduction, induction and deduction." 38

As we already discussed, attributing machine learning the capability of abduction is not without a twist. Charles Sanders Peirce and others reserved this late addition to the basic intellectual procedures of inference to creativity, interpretation, and ingenuity or interpretation from 1866 onwards. ${ }^{39}$ Abduction was carved out to be a stronghold of intellectual work as artists, intellectuals, theorists might see it: As unique, inexplainable ideas, emerging from a "je ne sais quoi" of learning, adorned with a spark of originality. Of course, abduction was dressed as a philosophical notion and defined as the moment of the selection of a hypothesis, which one might adopt for testing and further procedural, methodological work. Yet, a lot hinged on the moment of selection, which hypothesis to elaborate upon. It is here, where science is supplied with nascent theory, ideas, even new paradigms. ${ }^{40}$ This is why abduction is a valuable category to defend AI approaches. ${ }^{41}$

Kitchin builds a questionable opposition between data-driven science and knowledge-driven science, which he sees confined and trapped in deductive and sterile approaches. As a consequence, machine learning, of all things, now wins the price of finding new patterns. This turns

\footnotetext{
; Deuber-Mankowsky, Astrid. 'Zwischen Apokalypse Und Sym-Poiesis : Neue Materialismen Und Situiertes Wissen'. In Verantwortung Und Un/Verfügbarkeit: Impulse Und Zugänge Eines (Neo)Materialistischen Feminismus, edited by Corinna Bath et al., 151-65. Münster: Westfälisches Dampfboot, 2017..

${ }^{37}$ Krüger, Lorenz, Gerd Gigerenzer, and Mary S. Morgan, eds. The Probabilistic Revolution, Volume 2. Cambridge: MIT Press, 1987.

${ }^{38}$ Kitchin, Rob. 'Big Data, New Epistemologies and Paradigm Shifts'. Big Data \& Society 1, no. 1 (2014.): 1-12. Most epistemological reflections on AI methods depart from epistemological notions derived from a pre-Reichenbach philosophy of science, where the context of discovery with its practices, messiness and trial and error techniques is not taken into account. Scientific method and data seem to have not history, no context and are only reflected upon as idealized versions of themselves.

${ }^{39}$ Peirce, Charles Sanders. Collected Papers of Charles Sanders Peirce, Volumes I and II: Principles of Philosophy and Elements of Logic. Edited by Charles Hartshorne and Paul Weiss. Cambridge, MA: Harvard University Press, 1931.

${ }^{40}$ Wirth, Uwe. 'Abductive Reasoning in Peirce's and Davidson's Account of Interpretation'. Transactions of the Charles S. Peirce Society 35, no. 1 (1999): 115-27, 120f..; Plutynski, Anya. 'Four Problems of Abduction: A Brief History'. HOPOS: The Journal of the International Society for the History of Philosophy Of 1, no. 2 (2011): 227-48.

${ }^{41}$ Kitchin refers to the following discussions on abduction; Kelling, Steve et al. 'Data-Intensive Science: A New Paradigm for Biodiversity Studies'. BioScience 59, no. 7 (2009): 613-620. and Miller, Harvey J. 'The Data Avalanche Is Here. Shouldn't We Be Digging?' Journal of Regional Science 50, no. 1 (3 February 2010): 181-201.
} 
around the assumption by Pasquinelli and others that machine learning will be utterly unable to produce anything new and is incapable of any discovery in the proper sense. Kitchin avoids the term "discovery", but stresses frequently how machine learning will help to identify patterns no human could have hoped to observe. Potential obviously lies with long-term data series or complex systems, which require supra-human capacities for analysis. ${ }^{42}$

\section{Bias in classification and clustering}

But what kind of discovery and exploration is technically feasible, which would replace classical domains of thinking? What "kinds" of intelligence can we expect to emerge? ${ }^{43}$ As we have seen, Chris Anderson maintained that correlation would supersede causation as a main epistemological practice. ${ }^{44}$ Correlations could be traced everywhere and seem to hinge on the area last conquered by informatics, namely independent pattern recognition within large data sets (like language or images). ${ }^{45}$ The potential for new thinking, which Kitchin chooses to describe as the machines' ability to abductive inference, hinges on new correlations and on clustering. Just as data journalism starts out with a numerical irregularity and fills in the story later, ${ }^{46}$ it is plausible for Kitchin to point to the new abilities of algorithms, or increasingly artificial neuronal networks, to identify patterns and to produce new insights. ${ }^{47}$ Kitchin's term for this type of machine learning apart from abduction is "statistical exploration," 48 and some of the new developments he reports are less surprising when evaluated within the history of statistics. There is a slow development towards the immense distances between a factoid or data point and its eventual analysis in data driven science, which are bridged by various forms of processing and are currently turning data almost into a polyvalent abstraction such as money. There are several steps towards this distance in the history of statistics and apart from its proximity to informatics AI is generally described as having a decidedly 'statistical anatomy'. ${ }^{49}$

\footnotetext{
${ }^{42}$ Laubichler, Manfred D., Jane Maienschein, and Jürgen Renn. 'Computational History of Knowledge: Challenges and Opportunities'. Isis 110, no. 3 (2019): 502-12.; Laubichler, Manfred D., Jane Maienschein, and Jürgen Renn. 'Computational Perspectives in the History of Science: To the Memory of Peter Damerow'. Isis 104 (2014): 119-30.

${ }^{43}$ Malabou, Catherine. Morphing Intelligence. Translated by Carolyn Shread. New York: Columbia University Press, 2019.

44 Anderson, Chris. 'The End of Theory: The Data Deluge Makes the Scientific Method Obsolete'. WIRED, 23 June 2008. https://www.wired.com/2008/06/pb-theory/.

${ }^{45}$ Among the classical achievements of AI are pattern and speech recognition, as well as winning in Alpha Go (2015/16); Alibaba's reading comprehension (2018), writing texts with GPT 3 (2020) and debating (Project debater 2021) Slonim, Noam,et al. 'An Autonomous Debating System'. Nature 591 (2021): 379-384.; Jobin, Anna et al. 'AI Reflections in 2020'. Nature Machine Intelligence 8 (2021): $2-8$.

${ }^{46}$ Broussard, Meredith. Artificial Unintelligence. How Computers Misunderstand the World. Cambridge: MIT, 2018.

${ }^{47}$ The abductive capacities find a parallel of course in the argumentation with the "paradigm," derived from Thomas Kuhns model of scientific progress: Only now it is up to machine learning to identify an "anomaly", an incongruence with former theorems, which kicks off new theorizing, which may lead to a new research paradigm.

Kitchin, Rob. 'Big Data, New Epistemologies and Paradigm Shifts'. Big Data \& Society 1, no. 1 (2014.): 3. See on algorithmic exploration Kitchin, Rob. 'Thinking Critically about and Researching Algorithms'. Information, Communication \& Society 20, no. 1 (2017): $14-29$.

${ }^{49}$ Alpaydin, Ethem. Machine Learning. The New AI. Cambridge, MA: MIT Press, 2016.
} 
Within the recent history of statistics, the tendency is not to look at the quality and amount of singular data points, but at data practices, data journeys and the crucial element of building and choosing categories for data collection. The best researched example of the present changes in classificatory regimes within the history of science probably emerged within the history of the life sciences. ${ }^{50}$ Clustering has a longer history itself, but it is core to the recent technological success story of ANN. The procedure learned by machines replaces classification.

Sabina Leonelli and Marcel Boumans describe, how clustering is achieved by algorithms in business cycle data in economics and in biological taxonomy. Clustering does emerge from older data practices, specific to each discipline. While in the example from economics, timeframes and circles had to be defined and spotted, in the case from biodiversity research knowing types and recognizing shapes is crucial. The epistemological necessity of clustering in the respective research examples is described as a process of tidying and ordering, a procedure, which opens the data up for the subsequent analysis, but bears all the mark of a decisive step. The authors refer to Mary Douglas' conceptual framework of cleanliness and dirt as powerful social order. ${ }^{51}$ Thus not only phenotyping, fieldwork, photography and timespans, but also the clusters of information identified by automated 'thinking' are discussed in the proximity of categories, which have a direct bearing on social order. The most creative part of data driven research, the abductive inference of machines, is thus identified as a social technology.

This could be elucidated and sustained with many findings from the history colonial statistics, in ways that sometimes escape the emerging literature on present "data colonialism". 52 Statistical classification in British India is said to have stabilized and perpetuated the caste system, and legal categories in the colonies lead to the construction of the group "indigenous." 53 The

\footnotetext{
${ }^{50}$ Leonelli, Sabina. 'Classificatory Theory in Data-Intensive Science: The Case of Open Biomedical Ontologies'. International Studies in the Philosophy of Science 26, no. 1 (2012): 47-65.; Bowker, Geoffrey C. 'Biodiversity Datadiversity'. Social Studies of Science 30, no. 5 (2001): 643-684.; Rheinberger, Hans-Jörg. 'Infra-Experimentality: From Traces to Data, from Data to Patterning Facts'. History of Science 49, no. 3 (2011): 337-348.; Seising, Rudolph. 'The Emergence of Fuzzy Sets in the Decade of the Perceptron-Lotfi A. Zadeh's and Frank Rosenblatt's Research Work on Pattern Classification'. Mathematics/Fuzzy Mathematics 6, no. 7 (2018): 227-246.

${ }^{51}$ Boumans, Marcel, and Sabina Leonelli. 'From Dirty Data to Tidy Facts: Clustering Practices in Plant Phenomics and Business Cycle Analysis'. In Data Journeys in the Sciences, edited by Sabina Leonelli and Niccollò Tempini, 79-101. Heidelberg: Springer, 2020.; Arabie, Phipps, Lawrence J. Hubert, and Geert De Soete. Clustering and Classification. Singapore: World Scientific, 1996.; Brunton, Steven L., and J. Nathan Kutz. 'Classification and Clustering'. In Data-Driven Science and Engineering: Machine Learning, Dynamical Systems, and Control, $154-94$. Cambridge, MA: Cambridge University Press, 2019.

${ }^{52}$ Couldry, Nick, and Ulises A. Mejias. 'Making Data Colonialism Liveable: How Might Data's Social Order Be Regulated?' Internet Policy Review 8, no. 2 (30 June 2019). https://doi.org/https://doi.org/10.14763/2019.2.1411.; Thatcher, Jim, David O’Sullivan, and Dillon Mahmoudi. 'Data Colonialism through Accumulation by Dispossession: New Metaphors for Daily Data'. Society and Space 34, no. 6 (2016): $990-1006$. https://doi.org/https://doi.org/10.1177\%2F0263775816633195. ; Tarnoff, Ben. 'The Data Is Ours!' Logic, 2 April 2018. https://logicmag.io/scale/the-data-is-ours/; Kavita, Philip. Civilizing Natures: Race, Resources, and Modernity in Colonial South India. New Brunswick, NJ: Rutgers University Press, 2004.; Tahu, Kukutai, and John Taylor, eds. Indigenous Data Sovereignty: Toward an Agenda. Acton: The Australian National University Press, 2016.; Rainie, Stephanie Carroll et al. 'Data as a Strategic Resource: Self-Determination, Governance, and the Data Challenge for Indigenous Nations in the United States'. International Indigenous Policy Journa 8, no. 2 (2017).

${ }^{53}$ Cohn, Bernard. 'The Census, Social Structure and Objectification in South Asia'. In An Anthropologist among the Historians and Other Essays, 224-254. Delhi: Oxford University Press, 1987.; Malègue, Fanny. 'The Empire in a Census Table: Enumerating the Population and Governing the French Caribbean Colonies after the Seven Years' War'. Histoire \& Mesure 2 (2018): 93-114.; Curtis, Bruce. The Politics of Population: State Formation, Statistics, and the Census of Canada, 1840-1875. Toronto: University of Toronto Press, 2001.; Raj, Kapil. 'Beyond Postcolonialism .... and Postpositivism: Circulation and the Global History Of'. Isis 104, no. 2 (2 June 2013 ): $337-47$.
} 
general performative impact of statistical categories is a topic, ${ }^{54}$ which becomes of direct importance for citizens, since most statistical categories were employed and built by state statistics, and clustering is used in all kinds of administrative purposes already. Both classification and automated clustering are haunted by racial and gender biases. ${ }^{55}$

From this perspective of new exclusions and an emerging landscape of colonialism, there are of course more complications than just categories. There are infrastructural problems, which concern access to calculative power and curated databases, which help to reproduce old asymmetries of global inclusion and exclusion. ${ }^{56}$ Some of the training sets used in AI research on a daily basis, bear the mark of colonial extraction: Famous samples, such as the Pima dataset on diabetes, were proven to be taken involuntarily from indigenous populations, such as the database of dreams described by Joana Radin or the faulty DNA testing used in the classification of US American populations. ${ }^{57}$ Indigenous groups frequently became the subject of high resolution studies (cf. UN Indigenous Peoples Council on Biocolonialism), which did pioneer certain interior dimensions, ranging from global blood-samples to the comprehensive tests sets conducted in Micronesia, where an attempt was made "collect traces of subjectivity itself, to make an archive of the inner contents of the mind." ${ }^{58}$ Data are becoming more intimate, just as machines are. ${ }^{59}$ In face of this newly emerging quality of data, methodological discussions take two ways, one eliminating the transcendental in the name of presence and becoming, ${ }^{60}$ the other oddly focusing on the underlying process of abstraction guiding the new intimacy of data. I will focus on the latter, probably less known approach:

\section{On separations and challenge}

Already early cybernetics was concerned with outsourced thinking and decision. Causation was delegated to more flexible, dynamic and decentralized structures, eerily parallel to what Hayek

\footnotetext{
${ }^{54}$ Hacking, Ian. 'Making Up People'. In Reconstructing Individualism, edited by Thomas C. Heller, Morton Sosna, and David E. Wellbery. Stanford, CA: Stanford University Press, 1985.; Bouk, Dan. 'The History and Political Economy of Personal Data over the Last Two Centuries in Three Acts'. Osiris 32, no. 1 (2017): 85-106.; Serra, Gerardo. 'Hail the Census Night': Trust and Political Imagination in the 1960 Population Census of Ghana.' Comparative Studies in Society and History 60, no. 3 (2018): 659-687.

${ }^{55}$ Myers West, Sarah, Meredith Whittaker, and Kate Crawford. 'Discriminating Systems: Gender, Race, and Power in AI'. AI Now Institute, 2019. https://ainowinstitute.org/discriminatingsystems.pdf.

${ }^{56}$ Dommann, Monika, and Max Stadler. 'Introduction'. In Data Centers : Edges of a Wired Nation, edited by Monika Dommann, Hannes Rickli, and Max Stadler, 8-29. Zürich: Lars Müller Publishers, 2020.

${ }^{57}$ Radin, Joana. "'Digital Natives”: How Medical and Indigenous Histories Matter for Big Data'. Osiris 32 (2017): 43-64.; TallBear, Kimberly. Native American Dna: Tribal Belonging and the False Promise of Genetic Science. Minneapolis: University of Minnesota Press, 2013.

${ }^{58}$ Lemov, Rebecca. 'Towards a Data Base of Dreams: Assembling an Archive of Elusive Materials, c. 1947-61'. History Workshop Journal Issue 67 (2009): 45-68.

${ }^{59}$ Angerer, Marie Luise: Zu den Bedingungen affektiver Milieus, in: Rebekka Ludewig und Angelika Seppi (Hg.): Angerer, Marie Luise. 'Zu Den Bedingungen Affektiver Milieus'. In Milieu Fragmente. Technologische Und Ästhetische Perspektiven, Ilinx Kollaborationen 3, edited by Rebekka Ludewig and Angelika Seppi, 119-129. Leipzig: Spector Books, 2020.; Lemov, Rebecca. 'Anthropology's Most Documented Man, ca. 1947: A Prefiguration of Big Data from the Big Social Science Era'. Osiris 32 (2017): 21-42.

${ }^{60}$ Barad, Karen. Meeting the Universe Halfway: Quantum Physics and the Entanglement of Matter and Meaning. Durham, NC: Duke University Press, 2007.; Barad, Karen. 'Quantum Entanglements and Hauntological Relations of Inheritance: Dis/Continuities, Spacetime Infoldings, and Justice-to-Come'. Derrida Today 3 (2010): 240-68.
} 
described as the market. Since the onset of this technology, the automatization of thinking became an issue, for example in the 1961 conference at Karlsruhe ("Denkautomaten"), but also far earlier. ${ }^{61}$ These discussions of automated thinking resonate with the end of theory and the delegation of abduction to colonial machines. But recently there have been criticisms of the foundational dichotomy of man and machine thinking, which come from a classical materialist tradition of thinking with tools, not new materialism per se.

In this vein, David Chalmer's thesis that GPT -3 is the first algorithm capable of passing as automated thinking is scrutinized by Dutch and British Marxist media theory, namely Olya Kadina, Bas de Boer and James Steinhoff. What is unique to their approach is an economic and materialist reading of the very process of abstraction, which is conceived of as "form-determination." The principle of emancipating information from things is still one of the most central means of production for advanced capitalism and all the imbalances sustained by real abstraction (Realabstraktion). ${ }^{62}$ With data, money, metric systems, ratings and rankings populating the grids necessary to maintain capitalism, this language of pure functionalism is described as reified theory, as one side of the coin. The authors choose another perspective, where these separations do not occur or at least do not reign supreme. The resulting perspective is reminiscent of Ludmilla Hymans intriguing study of Russian epistemology and psychology of instruments. She characterizes them as a procedural, practical and "instrumental attitude to the world." The dichotomy of subject and tool is not maintained rigidly, but is resolved in favor of a more flexible coexistence with the biosphere, and its many tools and social structures, which are always, and with necessity, rewriting the way we think. It was a brand of Marxist psychology developed by Lev Vygotsky, Alexander Luria, and Alexei Nikolaevich Wassily Leontiev in the 1930s. ${ }^{63}$ Regarding computers Leontiev wrote:

"What functions do we relegate to the computer? All of the executive, operational part, which it does better than us anyway, because we think slowly (as in some eternal slumber). The machine also errs, but less frequently than us. It arms us, but the crucial thing is that as it arms us, it frees our thinking, and our thinking improves and thus creates new operations. And this process will continue to happen. They will only get smarter, these computers. And because they will always be progressing, we will also be getting

\footnotetext{
${ }^{61}$ Dick, Stephanie. 'AfterMath. The Work of Proof in the Age of Human-Machine Collaboration'. Isis 102, no. 3 (2011): 494-505.; Galison, Peter. 'Die Ontologie Des Feindes: Norbert Wiener Und Die Vision Der Kybernetik'. In Räume Des Wissens: Repräsentation, Codierung, Spur, edited by Hans-Jörg Rheinberger, Michael Hagner, and Bettina Wahrig-Schmidt, 281-324. Berlin: Akademie Verlag, 1997.; Bullock, Seth. 'Charles Babbage and the Emergence of Automated Reason'. In The Mechanical Mind in History, edited by Philip Husbands, Owen Holland, and Michael Wheeler, 19-40. Cambridge, Mass: MIT Pres, 2008.; MacKenzie, Donald. 'The Automation of Proof: A Historical and Sociological Exploration'. IEEE Annals of the History of Computing 17 (1995): 7-29.; Anderson, James A., and Edward Rosenfeld, eds. Talking Nets: An Oral History of Neural Networks. Cambridge, Mass: MIT Press, 1998.

${ }^{62}$ Elkins, Katherine, and Jon Chun. 'Can GPT-3 Pass a Writer's Turing Test?' Journal of Cultural Analytics 1, no. 1 (14 September 2020$)$. https://doi.org/https://doi.org/10.22148/001c.17212.; Floridi, Luciano, and Massimo Chiriatti. 'GPT-3: Its Nature, Scope, Limits, and Consequences'. Minds and Machines 30 (2020): 681-694.

${ }^{63}$ Hyman, Ludmila. Vygotsky on Scientific Observation. Preprint No. 375. Berlin: MPIWG, 2009.
} 
smarter on this account. And we will creatively define new cognitive problems and find new cognitive solutions. There will be development. Do you think that this development is new? That it was discovered in the era of computers? No. It has always existed, yet before this computer technology it existed on a lower level than what we are capable of now."64

Leontiev's optimistic remarks may be easily reconciled with a progressist version of historiography. Nevertheless the more contemporary example from the field of particle physics, as described above, also testifies to the fact that computers support and enhance "human" thinking instead of replacing it. Full automatisation thus seems to remain a choice.

\section{Preliminary conclusion}

A closer investigation of actual AI driven research projects shows that the alleged end of theory is particularly visible from a point of view, which privileges abstract categories of older philosophy of science over ethnographic or historical investigations of data practices. With Kitchin the suggestion would be not to relapse into ideological ideas of neutral data and objective quantification. As soon as modern and more finely grained epistemological concepts are drawn on, data and theory become inseparable in any search for evidence. Thus, theoretical thinking does not end, but seems to be rather challenged by the new tools provided by AI technology. This is not to say that there is no palpable shift in many disciplines towards a data driven research, or that sciences do all stay the same despite the new analytical possibilities. Particularly, we have pointed at automated clustering as a novelty, which Rob Kitchin even credited with the creativity of abductive potential. Any delegation of exploration to machines in this sensitive field of classificatory order raises mixed feelings, since the history of classification in statistics has shown the colonial impact of categories like ethnicity, gender, heavy worker, untouchable etc. Thus, automated classificatory schemes of data merit the data historian's full attention, and investigation into the ways in which AI changes science should depart from a thorough analysis of the laboratories, tools, helping hands, software, theories and research paradigms, applied contexts a particular research project is geared towards.

In the future, research on research related to $\mathrm{AI}$ will perhaps increasingly involve using machine learning to study machine learning (or using artificial neural networks to study artificial neural networks). A relevant hypothesis of such an account is that only AI systems might be able to substantially understand itself or other AI systems. And if this were true, one would have every reason to believe that at some point in the future only or essentially 'intelligent' machines can

\footnotetext{
${ }^{64}$ Hyman, Ludmila. Vygotsky on Scientific Observation. Preprint No. 375. Berlin: MPIWG, 2009, p. 23. She quotes Leontiev, A.N. Dejatel'nost', soznanije, lichnost' [Activity, consciousness, personality]. Moscow: Izdatel'stvo Politicheskoj Literatury, 1975, p. 345f.
} 
further optimize 'intelligent machines'. In the case of Alpha Go Zero, we have already been able to observe that the optimization of machine learning systems results from interaction with other machine learning systems as well with itself, which is why it is important to shed light on how AI systems might learn from each other or how they might be capable of studying themselves in the first place. However, the use of AI for current academic research consists only to a small extent in working on problems that push AI's performance to its limits. Accordingly, it seems important to us to explore the ordinary use of artificial neural networks and other AI tools, following the hypothesis that many scholars first strive to deploy standard AI methods before moving on to bigger challenges.

\section{Bibliography}

Adam, David, ed. 'From Brueghel to Warhol: AI Enters the Attribution Fray'. Nature 570 (2019).

Adams St. Pierre, Elizabeth. 'The Empirical and the New Empiricisms'. Cultural Studies, Critical Methodologies 16, no. 2 (2016): 111-124. https://doi.org/10.1177/1532708616636147.

Alpaydin, Ethem. Machine Learning. The New AI. Cambridge, MA: MIT Press, 2016.

Anderson, Chris. 'The End of Theory: The Data Deluge Makes the Scientific Method Obsolete'. WIRED, 23 June 2008. https://www.wired.com/2008/06/pb-theory/.

Anderson, James A., and Edward Rosenfeld, eds. Talking Nets: An Oral History of Neural Networks. Cambridge, Mass: MIT Press, 1998.

Angerer, Marie Luise. 'Zu Den Bedingungen Affektiver Milieus'. In Milieu Fragmente. Technologische Und Ästhetische Perspektiven, Ilinx Kollaborationen 3, edited by Rebekka Ludewig and Angelika Seppi, 119-129. Leipzig: Spector Books, 2020.

Arabie, Phipps, Lawrence J. Hubert, and Geert De Soete. Clustering and Classification. Singapore: World Scientific, 1996.

Aranova, Elena, Christine von Oertzen, and David Sepkoski. 'Introduction: Historicizing Big Data'. Osiris 32, no. 1 (2017): 1-17.

Barad, Karen. Meeting the Universe Halfway: Quantum Physics and the Entanglement of Matter and Meaning. Durham, NC: Duke University Press, 2007.

—. 'Quantum Entanglements and Hauntological Relations of Inheritance: Dis/Continuities, Spacetime Infoldings, and Justice-to-Come'. Derrida Today 3 (2010): 240-68.

Barnes, V. E. 'Observation of a Hyperon with Strangeness Minus Three'. Physical Review Letters 12, no. 8 (24 February 1964): 204-6.

Blaschke, Estelle. 'From Microform to the Drawing Bot: The Photographic Image as Data'. Grey Room 75 (2019): 60-83.

Bouk, Dan. 'The History and Political Economy of Personal Data over the Last Two Centuries in Three Acts'. Osiris 32, no. 1 (2017): 85-106.

Boumans, Marcel, and Sabina Leonelli. 'From Dirty Data to Tidy Facts: Clustering Practices in Plant Phenomics and Business Cycle Analysis'. In Data Journeys in the Sciences., edited by Sabina Leonelli and Niccollò Tempini, 79-101. Heidelberg: Springer, 2020.

Bourilkov, Dimitri. 'Machine and Deep Learning Applications in Particle Physics'. International Journal of Modern Physics A 34, no. 35 (2019): 1-29.

Bowker, Geoffrey C. 'Biodiversity Datadiversity'. Social Studies of Science 30, no. 5 (2001): 643-684.

Broussard, Meredith. Artificial Unintelligence. How Computers Misunderstand the World. Cambridge: MIT, 2018. 
Brown, Laurie M. 'The Rise of the Standard Model: 1964-1979'. In The Rise of the Standard Model. Particle Physics in the 1960s and 1970s, edited by Lillian Hoddeson, Laurie M. Brown, Michael Riordan, and Max Dresden, 3-35. New York: Cambridge University Press, 1997.

Brunton, Steven L., and J. Nathan Kutz. 'Classification and Clustering'. In Data-Driven Science and Engineering: Machine Learning, Dynamical Systems, and Control, 154-94. Cambridge, MA: Cambridge University Press, 2019.

Bullock, Seth. 'Charles Babbage and the Emergence of Automated Reason'. In The Mechanical Mind in History, edited by Philip Husbands, Owen Holland, and Michael Wheeler, 19-40. Cambridge, Mass: MIT Pres, 2008.

Clough, Patricia Ticiento. 'The New Empiricism: Affect and Sociological Method'. European Journal of Social Theory 12, no. 1 (2009): 43-61. https://doi.org/10.1177/1368431008099643.

Cohn, Bernard. 'The Census, Social Structure and Objectification in South Asia'. In An Anthropologist among the Historians and Other Essays, 224-254. Delhi: Oxford University Press, 1987.

Couldry, Nick, and Ulises A. Mejias. 'Making Data Colonialism Liveable: How Might Data's Social Order Be Regulated?' Internet Policy Review 8, no. 2 (30 June 2019). https://doi.org/https://doi.org/10.14763/2019.2.1411.

Curtis, Bruce. The Politics of Population: State Formation, Statistics, and the Census of Canada, 1840-1875. Toronto: University of Toronto Press, 2001.

Deuber-Mankowsky, Astrid. 'Zwischen Apokalypse Und Sym-Poiesis : Neue Materialismen Und Situiertes Wissen'. In Verantwortung Und Un/Verfügbarkeit : Impulse Und Zugänge Eines (Neo)Materialistischen Feminismus, edited by Corinna Bath, Hanna Meißner, Stephan Trinkaus, and Susanne Völker, 151-65. Münster: Westfälisches Dampfboot, 2017.

Dick, Stephanie. 'AfterMath. The Work of Proof in the Age of Human-Machine Collaboration'. Isis 102, no. 3 (2011): 494-505.

Dommann, Monika, and Max Stadler. 'Introduction'. In Data Centers : Edges of a Wired Nation, edited by Monika Dommann, Hannes Rickli, and Max Stadler, 8-29. Zürich: Lars Müller Publishers, 2020.

Elgin, Catherine. With Reference to Reference. Indianapolis: Hackett, 1983.

Elkins, Katherine, and Jon Chun. 'Can GPT-3 Pass a Writer's Turing Test?' Journal of Cultural Analytics 1, no. 1 (14 September 2020). https://doi.org/https://doi.org/10.22148/001c.17212.

Floridi, Luciano, and Massimo Chiriatti. 'GPT-3: Its Nature, Scope, Limits, and Consequences'. Minds and Machines 30 (2020): 681-694.

Friedman, Jerome. 'Deep-Inelastic Scattering and the Discovery of Quark'. In The Rise of the Standard Model. Particle Physics in the 1960s and 1970s, edited by Lillian Hoddeson, Laurie M. Brown, Michael Riordan, and Max Dresden, 566-88. New York: Cambridge University Press, 1997.

Galison, Peter. 'Die Ontologie Des Feindes: Norbert Wiener Und Die Vision Der Kybernetik'. In Räume Des Wissens: Repräsentation, Codierung, Spur, edited by Hans-Jörg Rheinberger, Michael Hagner, and Bettina Wahrig-Schmidt, 281-324. Berlin: Akademie Verlag, 1997.

- Image and Logic. A Material Culture of Microphysics. Chicago: University of Chicago Press, 1997.

Hacking, Ian. 'Making Up People'. In Reconstructing Individualism, edited by Thomas C. Heller, Morton Sosna, and David E. Wellbery. Stanford, CA: Stanford University Press, 1985.

Hagen, Wolfgang. 'Das Atlantische Standard Modell - Anmerkungen Zu Einer Genealogie Der Elektrizität Und Ihrer Medien', 2014. http://www.whagen.de/PDFS/07953_HagenDasatlantischeStanda_2014.pdf. 
Hey, Tony, Stewart Tansley, and Kristin Tolle, eds. 'Jim Gray on EScience: A Transformed Scientific Method'. In The Fourth Paradigm: Data-Intensive Scientific Discovery, xvii-xxxi, xviii. Microsoft Research, 2009. 2009.

Hey, Tony, and Anne Trefethen. 'The Fourth Paradigm 10 Years On'. Informatik Spektrum 42 (2020): 441-447.

How is Artificial Intelligence Changing Science? 'AI Projects in Europe', 2021. https://howisaichangingscience.eu/ai-projects-in-europe/.

Hyman, Ludmila. Vygotsky on Scientific Observation. Preprint No. 375. Berlin: MPIWG, 2009.

Jobin, Anna, Kingson Man, Antonio Damasio, Georgios Kaissis, and Rickmer Braren. 'AI Reflections in 2020'. Nature Machine Intelligence 8 (2021): 2-8.

Kavita, Philip. Civilizing Natures: Race, Resources, and Modernity in Colonial South India. New Brunswick, NJ: Rutgers University Press, 2004.

Kelling, Steve, Wesley M. Hochachka, Daniel Fink, Mirek Riedewald, Rich Caruana, Grant Ballard, and Giles Hooker. 'Data-Intensive Science: A New Paradigm for Biodiversity Studies'. BioScience 59, no. 7 (2009): 613-620.

Kitchin, Rob. 'Big Data, New Epistemologies and Paradigm Shifts'. Big Data \& Society 1, no. 1 (2014): 1-12.

- 'Thinking Critically about and Researching Algorithms'. Information, Communication \& Society 20, no. 1 (2017): 14-29. https://doi.org/10.1080/1369118X.2016.1154087.

Krüger, Lorenz, Gerd Gigerenzer, and Mary S. Morgan, eds. The Probabilistic Revolution, Volume 2. Cambridge: MIT Press, 1987.

Laubichler, Manfred D., Jane Maienschein, and Jürgen Renn. 'Computational History of Knowledge: Challenges and Opportunities'. Isis 110, no. 3 (2019): 502-12.

- 'Computational Perspectives in the History of Science: To the Memory of Peter Damerow'. Isis 104 (2014): 119-30.

Lemov, Rebecca. 'Anthropology's Most Documented Man, ca. 1947: A Prefiguration of Big Data from the Big Social Science Era'. Osiris 32 (2017): 21-42.

_ 'Towards a Data Base of Dreams: Assembling an Archive of Elusive Materials, c. 1947-61'. History Workshop Journal Issue 67 (2009): 45-68.

Leonelli, Sabina. 'Classificatory Theory in Data-Intensive Science: The Case of Open Biomedical Ontologies'. International Studies in the Philosophy of Science 26, no. 1 (2012): 47-65.

Lynch, Shana. 'Andrew Ng: Why AI Is the New Electricity'. Stanford Graduate School of Business, 3 November 2017. https://www.gsb.stanford.edu/insights/andrew-ng-why-ai-new-electricity.

MacKenzie, Donald. 'The Automation of Proof: A Historical and Sociological Exploration'. IEEE Annals of the History of Computing 17 (1995): 7-29.

Malabou, Catherine. Morphing Intelligence. Translated by Carolyn Shread. New York: Columbia University Press, 2019.

Malègue, Fanny. 'The Empire in a Census Table: Enumerating the Population and Governing the French Caribbean Colonies after the Seven Years' War'. Histoire \& Mesure 2 (2018): 93114.

McDaniel, John, and Ken Pease, eds. Predictive Policing and Artificial Intelligence. Abingdon, New York: Taylor \& Francis, 2021.

Metzler, Marco. 'Jürgen Schmidhuber: «Die Geschichte Wird Nicht Mehr von Menschen Dominiert»'. NZZ am Sonntag, 21 2017. https://nzzas.nzz.ch/gesellschaft/juergen-schmidhuber-geschichte-wird-nicht-mehr-von-menschen-dominiert-ld.1322558?reduced=true\#back-register.

Miller, Harvey J. 'The Data Avalanche Is Here. Shouldn't We Be Digging?' Journal of Regional Science 50, no. 1 (3 February 2010): 181-201. 
Myers West, Sarah, Meredith Whittaker, and Kate Crawford. 'Discriminating Systems: Gender, Race, and Power in AI'. AI Now Institute, 2019. https://ainowinstitute.org/discriminatingsystems.pdf.

Pasquinelli, Matteo. 'Machines That Morph Logic: Neural Networks and the Distorted Automation of Intelligence as Statistical Inference'. Logic Gate: The Politics of the Artifactual Mind, 2017. https:/www.glass-bead.org/article/machines-that-morph-logic/?lang=enview.

Peirce, Charles Sanders. Collected Papers of Charles Sanders Peirce, Volumes I and II: Principles of Philosophy and Elements of Logic. Edited by Charles Hartshorne and Paul Weiss. Cambridge, MA: Harvard University Press, 1931.

Pickering, Andrew. Constructing Quarks. A Sociological History of Particle Physics. Chicago: University of Chicago Press, 1984.

Plutynski, Anya. 'Four Problems of Abduction: A Brief History'. HOPOS: The Journal of the International Society for the History of Philosophy Of 1, no. 2 (2011): 227-48.

Radin, Joana. "'Digital Natives": How Medical and Indigenous Histories Matter for Big Data'. Osiris 32 (2017): 43-64.

Radovic, Alexander, Mike Williams, David Rousseau, Michael Kagan, Daniele Bonacorsi, Alexander Himmel, Adam Aurisano, Kazuhiro Terao, and Taritree Wongjirad. 'Machine Learning at the Energy and Intensity Frontiers of Particle Physics'. Nature 560 (2018): 41-48.

Rainie, Stephanie Carroll, Jennifer Lee Schultz, Eileen Briggs, Patricia Riggs, and Nancy Lyn Palmanteer-Holder. 'Data as a Strategic Resource: Self-Determination, Governance, and the Data Challenge for Indigenous Nations in the United States'. International Indigenous Policy Journa 8, no. 2 (2017).

Raj, Kapil. 'Beyond Postcolonialism ... and Postpositivism: Circulation and the Global History Of'. Isis 104, no. 2 (2 June 2013): 337-47.

Ramsch, Jesper Sören. '70 Years of Machine Learning in Geosciencein Review'. Advances in Geophysics 61 (2020): 1-55. https://doi.org/https://doi.org/10.1016/bs.agph.2020.08.002.

Rheinberger, Hans-Jörg. 'Infra-Experimentality: From Traces to Data, from Data to Patterning Facts'. History of Science 49, no. 3 (2011): 337-348.

Samios, Nicholas. 'Early Baryon and Meson Spectroscopy Culminating in the Discovery of the Omega Minus SU(3) and Quarks'. Stanford: Brookhaven National Lab., 1993. https://www.osti.gov/biblio/10162083.

- 'Early Baryon and Meson Spectroscopy Culminating in the Discovery of the OmegaMinus and Charmed Baryons'. In The Rise of the Standard Model. Particle Physics in the 1960s and 1970s, edited by Lillian Hoddeson, Laurie M. Brown, Michael Riordan, and Max Dresden, 525-41. New York: Cambridge University Press, 1997.

Schaffer, Simon. 'Newton on the Beach: The Information Order of Principia Mathematica'. History of Science 47, no. 3 (2009): 243-76. https://doi.org/10.1177/007327530904700301.

Seising, Rudolph. 'The Emergence of Fuzzy Sets in the Decade of the Perceptron-Lotfi A. Zadeh's and Frank Rosenblatt's Research Work on Pattern Classification'. Mathematics/Fuzzy Mathematics 6, no. 7 (2018): 227-246.

Senior, Andrew, John Jumper, Demis Hassabis, and Pushmeet Kohli. 'AlphaFold: Using AI for Scientific Discovery'. Deep Mind (blog), 15 January 2020. https://deepmind.com/blog/article/AlphaFold-Using-AI-for-scientific-discovery.

Serra, Gerardo. 'Hail the Census Night': Trust and Political Imagination in the 1960 Population Census of Ghana.' Comparative Studies in Society and History 60, no. 3 (2018): 659-687.

Siegert, Bernhard. 'Inquisition Und Feldforschung: Zur These Michel Foucaults Über Die Genese Der Empirischen Wissenschaften Im 16. Jahrhundert'. Modern Language Notes, German Issue 118, no. 3 (2003): 538-56.

Slonim, Noam, Yonatan Bilu, Carlos Alzate, Roy Bar-Haim, Ben Bogin, and Francesca Bonin. 'An Autonomous Debating System'. Nature 591 (2021): 379-384. 
Strand, R.C. 'Man-Machine Cooperation in Digital Pattern Recognition of Bubble Chamber Tracks'. Annals of the New York Academy of Sciences 157, no. 1 (1967): 65-82.

Sudmann, Andreas. 'Einleitung'. In Machine Learning. Medien, Infrastrukturen und Technologien der Künstlichen Intelligenz, by Christoph Engemann and Andreas Sudmann, XX. Bielefeld: Transcript, 2018.

. 'Szenarien des Postdigitalen. Deep Learning als MedienRevolution'. In Machine Learning. Medien, Infrastrukturen und Technologien der Künstlichen Intelligenz, by Christoph Engemann and Andreas Sudmann, 56-73. Bielefeld: Transcript, 2018.

Tahu, Kukutai, and John Taylor, eds. Indigenous Data Sovereignty: Toward an Agenda. Acton: The Australian National University Press, 2016.

TallBear, Kimberly. Native American Dna: Tribal Belonging and the False Promise of Genetic Science. Minneapolis: University of Minnesota Press, 2013.

Tanz, Jason. 'Soon We Won't Program Computers. We'll Train Them Like Dogs'. WIRED, 17 May 2017. https://www.wired.com/2016/05/the-end-ofcode $/$ ? code $=$ cf516G16Cxh0Jr_HDAVrbKvz21OtYXb0EhA9j7Rkw_D\&state $=\% 7 \mathrm{~B} \% 22$ redirectURL $\% 22 \% 3 \mathrm{~A} \% 22 \mathrm{https} \% 3 \mathrm{~A} \% 2 \mathrm{~F} \% 2 \mathrm{Fwww}$.wired.com $\% 2 \mathrm{~F} 2016 \% 2 \mathrm{~F} 05 \% 2 \mathrm{Fthe}$-end-of-

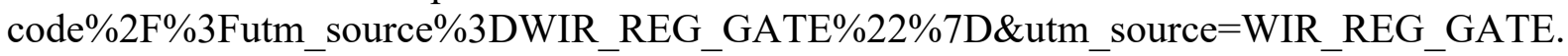

Tarnoff, Ben. 'The Data Is Ours!' Logic, 2 April 2018. https://logicmag.io/scale/the-data-isours/.

Thatcher, Jim, David O'Sullivan, and Dillon Mahmoudi. 'Data Colonialism through Accumulation by Dispossession: New Metaphors for Daily Data'. Society and Space 34, no. 6 (2016): 990-1006. https://doi.org/https://doi.org/10.1177\%2F0263775816633195.

Vinge, Vernor. 'The Coming Technological Singularity: How to Survive in the Post-Human Era'. VISION-21 Symposium, 1993, 11-22. https://ntrs.nasa.gov/archive/nasa/casi.ntrs.nasa.gov/19940022855.pdf.

Webb, Sarah. 'Deep Learning for Biology'. Nature 554 (2018): 555-57.

Wirth, Uwe. 'Abductive Reasoning in Peirce's and Davidson's Account of Interpretation'. Transactions of the Charles S. Peirce Society 35, no. 1 (1999): 115-27, $120 \mathrm{f}$. 